\title{
IDEÁRIOS, CONCEPÇÕES E PRÁTICAS NA FORMAÇÃO DE PROFESSORES DA REDE MUNICIPAL DE CURITIBA
}

\author{
Alboni Marisa Dudeque Pianovski Vieira \\ Pontifícia Universidade Católica do Paraná - PUCPR \\ alboni.vieira@pucpr.br
}

\section{RESUMO}

No período compreendido entre 1979 e 1992, quatro propostas educacionais foram adotadas pela Rede Municipal de Ensino de Curitiba, correspondendo às gestões dos prefeitos Jaime Lerner (1979-1983 e 1989-1992), Maurício Fruet (1983-1985) e Roberto Requião (1985-1989). Essas propostas corresponderam a momentos históricos distintos, que suscitaram tendências educacionais diferenciadas, com efeito direto no fazer pedagógico dos professores e que, como consequência, repercutiram de forma diferenciada no tratamento da formação continuada de professores. O objetivo deste estudo é analisar os diferentes ideários, concepções e práticas pedagógicas no período, com os estilos de formação docente deles resultante. A pesquisa, de caráter bibliográfico e documental, foi realizada com apoio nos trabalhos de Poulantzas (2000), Saviani (2005), Miguel e Vieira (2006), Vieira (2010) e nos documentos disponibilizados pelos Arquivos do IPPUC e da Secretaria Municipal de Educação. Como resultado, foi possível identificar relações entre ideários, concepções e práticas pedagógicas e a formação docente no período estudado.

Palavras-chave: Ideários, concepções e práticas pedagógicas. Rede Municipal de Ensino de Curitiba. Formação continuada de professores.

\section{IDEOLOGY, CONCEPTIONS AND PRACTICES IN THE EDUCATION OF TEACHERS IN THE MUNICIPAL SCHOOL NETWORK OF CURITIBA}

\begin{abstract}
Between 1979 and 1992, four educational proposals were adopted by the Municipal School Network of Curitiba, corresponding to the managements of the mayors Jaime Lerner (1979-1983 and 1989-1992), Maurício Fruet (1983-1985) and Roberto Requião (19851989). These proposals correspond to distinct historical moments that elicited different educational trends, with direct effect on teaching tasks and, as a consequence, different effects in the treatment of continuous education of teachers. The objective of this study is to analyze the various ideologies, conceptions and teaching practices in the period, with the teacher training styles that resulted. The research, of bibliographic and documentary nature, was carried out with support in the work of Poulantzas (2000), Saviani (2005), Miguel and Vieira (2006), Vieira (2010) and in the documents provided by IPPUC's and City Department of Education's Files. As a result, it was possible to identify relationships between ideology, concepts and teaching practices and teacher training in the studied period.
\end{abstract}

Keywords: Ideology, conceptions and teaching practices. Municipal School Network of Curitiba. Continuous education of teachers. 


\section{Introdução}

Estudar o ensino no Município de Curitiba apresenta interesse especial ao pesquisador, sobretudo considerando-se alguns fatores que, na segunda metade do século $\mathrm{XX}$, lhe conferiram características próprias. Uma dessas características foi a decisão do Município de assumir a responsabilidade pela educação, na vigência da Lei de Diretrizes e Bases da Educação Nacional - Lei no 4.024, de 20 de dezembro de 1961 (BRASIL, 1961), em que não havia essa previsão. Outra, a pouca alternância de partidos políticos na gestão do município, permitindo que idéias políticas, científicas, econômicas e sociais se consolidassem e possibilitassem a implantação de concepções e práticas educacionais que tiveram vigência por longo tempo.

Com o objetivo de melhor contextualizar historicamente a educação no Município de Curitiba, será feita breve menção a alguns aspectos da educação no Município anteriores ao início do período em estudo.

Pode-se considerar que, até 1963, era incipiente a organização administrativa do Município no que se referia às competências na área educacional. Embora o número de escolas públicas construídas pelo Município viesse aumentando, em face do aumento da população, os prédios escolares, uma vez construídos, eram cedidos ao governo estadual, que assumia a contratação de professores e a efetivação do trabalho pedagógico.

Com a criação da Comissão de Planejamento Educacional do Município de Curitiba, pelo Decreto n ${ }^{\circ} 1.014 / 63$, na gestão do prefeito Ivo Arzua Pereira, iniciaram-se os trabalhos com a finalidade de colaborar com a administração municipal na orientação didática e na programação do Centro Experimental da Vila Leão, que viria a se constituir no $1^{\circ}$ Centro Comunitário em Curitiba. O pressuposto para essa iniciativa era a necessidade de um planejamento integrado que visasse a propiciar condições de desenvolvimento global da população, o qual, por sua vez, exigiria o conhecimento da realidade do ensino no Município. Só assim se poderia "chegar a definir uma Política Educacional e estabelecer critérios mais válidos para o Planejamento Físico Territorial, de maneira a favorecer o desencadeamento do processo de promoção humana" (CURITIBA, 1968, p. 1).

A Vila Leão, local escolhido para instalação do $1^{\circ}$ Centro Comunitário, que foi denominado Papa João XXIII, era periférica ao centro da cidade, sendo habitada predominantemente por operários de indústrias de beneficiamento de madeira e de móveis. A proposta de uma educação integral que abrangesse alunos e familiares residentes na Vila Leão, possibilitando-lhes uma elevação no nível de renda, era uma iniciativa pioneira do Município de Curitiba. O Centro Comunitário Papa João XXIII, que serviu de modelo para os demais Centros que foram instalados, era composto por um grupo escolar e por clubes de interesses: agrícola, de recreação orientada, de educação doméstica, de leitura, das donas de casa; além disso, havia o centro de artes industriais, a escolinha de artes, a biblioteca comunitária e o setor da unidade sanitária polivalente.

A localização dos Centros Comunitários ocorria em setores delimitados pelo Instituto de Pesquisa e Planejamento Urbano de Curitiba (IPPUC), vinculados ao Plano Diretor da cidade. Assim, dando continuidade ao processo, foram criados dois outros Centros Comunitários - Professora Isolda Schmit (1966) e Nossa Senhora da Luz dos Pinhais (1967), respectivamente, no Conjunto Residencial do Pilarzinho e no Conjunto Nossa Senhora da Luz dos Pinhais.

Em 1963, atuavam na rede municipal 23 docentes mantidos pelo Estado, número que se ampliou para 29 em 1964, vindo a diminuir a partir de 1965, com a ampliação do número de docentes sob responsabilidade municipal (CURITIBA, 1966, p. 6). Com a 
ampliação dos programas sociais, percebia-se que era necessário atuar na capacitação docente, considerando-se que as carências do ponto de vista qualitativo, nesse aspecto, eram acentuadas. Algumas atividades foram, então, desenvolvidas com o objetivo de qualificar o professorado, como a oferta de cursos e o estímulo à realização de encontros pedagógicos.

Os resultados trazidos às comunidades pelos Centros nelas instalados foram significativos, sobretudo em função da elevação do nível sócio-econômico-cultural. Muitas das associadas dos Clubes das Donas de Casa, por exemplo, haviam conseguido sua independência econômica com a profissão de costureiras, contribuindo para o equilíbrio do orçamento familiar. $\mathrm{O}$ cuidado com a aparência pessoal e com o ambiente doméstico havia igualmente melhorado (CURITIBA, 1969). Esses resultados auspiciosos estimularam o surgimento de uma diversidade de atividades curriculares voltadas para o desenvolvimento integral do homem e sua participação efetiva na obra do bem comum.

Em 1968, foi implantado o $1^{\circ}$ Plano de Educação da Rede Municipal de Curitiba. Esse Plano havia sido elaborado por técnicos do Instituto de Pesquisa e Planejamento Urbano de Curitiba (IPPUC), com a assessoria do prof. Erasmo Pilotto (NEVES, 1988), de acordo com as recomendações do Plano Diretor da cidade. Previa que o Município assumiria os encargos referentes à educação de nível pré-primário e primário, ficando o ensino médio para o âmbito estadual e o superior para o federal (CURITIBA, 1968).

De acordo com o $1^{\circ}$ Plano de Educação,

[...] o progresso e o desenvolvimento social devem resultar da participação consciente de cada cidadão e reverter em benefício da coletividade; a responsabilidade de conscientizar e preparar o homem para assumir seu papel no mundo moderno, dentro de um conceito democrático, cabe, em grande parte, às instituições educacionais (CURITIBA, 1968, p. 1).

O $1^{\circ}$ Plano colaborou para a consolidação do Setor de Educação do IPPUC e para o início de sua experiência de planejamento na área social. A escolha do IPPUC para elaboração do trabalho se justificava pela "conjuntura em que se encontrava a cidade, pois, para cada diretriz de recondicionamento urbano, apareciam novas necessidades a ser resolvidas" (COSTA, 2007, p. 27). Afirmava-se a importância de serem propiciadas condições de desenvolvimento global para a população, com metas sociais que levassem o homem a se autopromover, de forma a que, aos poucos, pudessem ser substituídas as ações do Estado paternalista, cujo objetivo seria o de atender às necessidades básicas da população. O Plano apontava, assim, para um estado neoliberal, isento de proporcionar determinados serviços à população. Num mundo dominado pela tecnologia, as oportunidades seriam tão mais frequentes quanto mais especializados fossem os homens (CURITIBA, 1968).

As ações da Prefeitura Municipal de Curitiba, portanto, mostravam-se pautadas em uma filosofia de progresso e desenvolvimento, refletindo princípios do Welfare State Estado de bem-estar social. Esperava-se que a sociedade fosse suprida de benefícios sociais, que significariam segurança para manter o mínimo de base material e níveis de padrão de vida, para que pudesse enfrentar os efeitos deletérios de uma estrutura de produção capitalista desenvolvida e excludente, segundo Gomes (2006).

O $1^{\circ}$ Plano Educacional vigorou até o final do primeiro período de gestão do 
prefeito Jaime Lerner (1971-1975).

Considerando-se as características socioeconômicas das comunidades atendidas, em 1975 o Departamento de Educação da Prefeitura Municipal de Curitiba elaborou novo Plano de Educação, com a implantação de um Currículo único, em consonância com os dispositivos da Lei $\mathrm{n}^{\circ}$ 5.692, de 11 de agosto de 1971 (BRASIL, 1971). Como premissas, o Plano observava: a criança, como centro e objeto da educação; a escola, como agente específico da educação; a comunidade, como ponto de origem da criança; e a realização da humanidade, como fim da educação (CURITIBA, 1975b, p. 5-6).

A defasagem crescente entre o crescimento da população do município e a oferta de vagas para o ensino de $1^{\circ}$ grau suscitou a realização de estudo diagnóstico, em parceria como a Secretaria de Estado da Educação e Cultura e a Fundação Educacional do Paraná Fundepar. Desse estudo resultou a elaboração de um plano integrado, que permitiu a quase duplicação do número de Unidades Escolares pertencentes à Rede Municipal de Ensino. Pode-se inferir que o planejamento técnico, elaborado pelo setor especializado, não dava conta dos problemas sociais. A revisão das ações e metas se fazia imperiosas, para atender ao processo de urbanização acelerada de Curitiba, característico do capitalismo periférico.

Nos anos que se seguiram, expandiu-se a rede escolar municipal, aumentando-se o número de salas de aula e também o número de professores: em 1973, havia 711 docentes; em 1976, esse número havia aumentado para 1.211 professores (CURITIBA, 1976).

É a partir de 1979, quando se elaborou, com a colaboração do IPPUC, o "Programa Municipal de Educação - 1980/1984 -, contendo aspectos referentes às tendências, comportamentos e evolução da situação sócio-econômica, demográfica e de escolaridade do Município de Curitiba" (CURITIBA, 1979, p.5), que se inicia a reflexão objeto deste artigo. Os planos e programas subseqüentes, no entanto, estão imbricados ao contexto até aqui apresentado, ora por lhe darem continuidade, ora por tentarem romper com ele.

Analisar e estabelecer relações entre os ideários e as concepções que informaram a atuação na esfera educacional durante os períodos de governo de Jaime Lerner (1979-1983 e 1989-1992), Maurício Fruet (1983-1985) e Roberto Requião (1985-1989), gerando práticas pedagógicas distintas e uma formação continuada docente em que ficaram muito claros aqueles fundamentos, constitui o objetivo deste trabalho.

Adotou-se, como periodização, a subdivisão proposta por Miguel e Vieira (2006), relativa à educação no município de Curitiba, que considera o período de 1963 a 1968 como de implantação do sistema municipal de ensino, trazendo, na sequência:

1968-1975 - $1^{\circ}$ Plano Educacional, elaborado pelos técnicos do IPPUC.

1975-1979 - 2º Plano Educacional, elaborado pelo Departamento de Educação da Prefeitura Municipal.

1979-1983 - $3^{\circ}$ Plano Educacional, elaborado pelo Departamento de Educação, no segundo período de governo de Jaime Lerner.

1983-1986 - Publicação do manifesto "Políticas da Educação para uma Escola Aberta", elaborado a partir das discussões e reflexões entre os profissionais da Rede Municipal de Ensino de Curitiba.

1986-1989 - Plano de Educação do Município de Curitiba, elaborado pela Secretaria Municipal de Educação, na gestão do prefeito Roberto Requião.

1989-1992 - Plano Municipal de Ensino, elaborado pela Secretaria Municipal de Ensino de Curitiba, no terceiro período de Jaime Lerner como prefeito.

Em termos de fundamentação teórica, o diálogo com Gramsci (2000) e Poulantzas (2000) possibilitou interpretar o contido nos documentos pesquisados à luz das concepções de Estado e de sociedade. Nos estudos de Bloch (2001) se aprofundou a compreensão da função da história. Farge (2009) estimulou a consulta aos arquivos do Instituto de Pesquisa 
e Planejamento Urbano de Curitiba (IPPUC) e da Secretaria Municipal da Educação, para que se percebesse que "a história não é jamais a repetição do arquivo, mas desinstalação em relação a ele" (FARGE, 2009, p. 75). A discussão sobre as concepções que informaram a educação na Rede Municipal de Ensino, em suas relações com o modo de produção foram amparadas pelas reflexões de Zanella (2003) e Saviani (2005). No que se refere aos estudos sobre a educação no município de Curitiba e a formação de professores, Miguel (1997), Miguel e Vieira (2006) e Vieira (2010), forneceram valiosos subsídios.

No período em estudo, o ensino fundamental em Curitiba sofreu a influência de diferentes políticas educacionais, cada uma com características próprias, que nem sempre se coadunavam com a continuidade de programas implantados em gestões anteriores. Há momentos em que a mudança de paradigma na esfera educacional traz a substituição de propostas em andamento, causando interrupção no trabalho dos professores e insuficiente clareza sobre a legitimidade de tais ações.

A reconstrução de uma parte da história da educação no município de Curitiba aqui elaborada, a partir de documentos, tem como objetivo auxiliar na descoberta da "força da solidariedade das épocas e os laços de inteligibilidade [que] entre elas se tecem verdadeiramente nos dois sentidos “(BLOCH, 2001, p. 54).

Como resultado, espera-se demonstrar como ideários, concepções e práticas pedagógicas diferenciadas, no período 1979-1992 geraram estilos igualmente diferenciados de formação docente.

\section{Desenvolvimento}

\section{As políticas públicas educacionais}

O tratamento dado às políticas educacionais é resultante das políticas públicas, nas quais se traduzem os modos de articulação entre o Estado e a sociedade, neles considerados a divisão social do trabalho e as relações de produção.

Para as análises subseqüentes optou-se pela concepção de Estado elaborada por Gramsci, que rejeita a concepção clássica do "Estado guardião", da época liberal, considerando a sociedade política como uma extensão da sociedade civil, não havendo antítese entre sociedade civil e Estado. Explica Gramsci (2000, p. 226), que a sociedade civil "corresponde à função de hegemonia que o grupo dominante exerce em toda a sociedade", ao domínio privilegiado da ideologia, espaço em que a classe fundamental deve assegurar o consenso socialmente necessário ao exercício do seu poder econômico e político.

Inspirado em Gramsci, Poulantzas (2000) acrescenta que as transformações nas relações de produção sugerem modificações na constituição e reprodução das classes sociais e nas estruturas de poder e de dominação. O Estado, em relação às classes dominantes, "tem um papel principal de organização" (POULANTZAS, 2000, p. 128). É ele que representa e organiza as classes dominantes e o interesse político em longo prazo do bloco no poder. A política de Estado deve ser considerada, portanto, como a resultante das contradições de classe inseridas na própria estrutura do Estado, sendo que são essas contradições que constituem o Estado.

Essa condição leva o Estado a exercer sua política global em favor da classe ou fração hegemônica, que atualmente é o capital monopolista. O Estado capitalista, desta forma, apresenta-se como representante do "interesse geral" de grupos concorrentes: simultaneamente, ele é o Estado popular, racional e de classe. Assim, mesmo representando os interesses políticos de classe, o Estado comporta, em suas estruturas, um 
jogo de força que permite o reconhecimento dos interesses do trabalho, dentro de determinados limites. A estratégia acionada pela dominação hegemônica das classes dominantes, em busca de "consentimento", permite que sejam atendidos determinados interesses de certas classes dominadas, ainda que, eventualmente, contrariem os interesses econômicos predominantes, desde que sejam compatíveis com os interesses políticos e, via de regra, com a dominação hegemônica. Disto resulta que, no Estado capitalista, dominado pela burguesia, os interesses das classes subalternas também estejam, de alguma forma, representados (POULANTZAS, 2000).

As políticas educacionais, sob esse ponto de vista, não são apenas um requisito para a reprodução das condições materiais de produção, mas um elemento fundamental da própria sociabilidade capitalista. Considerando-se a implantação dos sistemas públicos de ensino e o seu caráter obrigatório e universal, "a regulação estatal sobre a educação, conjugada a outras políticas públicas, constitui-se, assim, numa das estratégias para regular e manter a possibilidade e continuidade do trabalho assalariado" (AZEVEDO, 2004, p. 50).

As políticas educacionais, no bojo das políticas públicas, dependem do jogo de forças presentes no aparelho de Estado. As contradições de classe inseridas na estrutura do Estado, as quais constituem o próprio Estado, acabam gerando a prevalência de um ou outro grupo na gestão da máquina governamental, cujos interesses serão refletidos nas políticas educacionais.

No período abrangido por este estudo, serão também considerados os fatores originados num contexto global, sob a ótica do modo de produção capitalista, a forma de sua absorção pela elite política nacional e municipal, bem como por outros segmentos organizados da sociedade civil.

Com a concentração dos meios de produção nas mãos de poucos capitalistas, que precisavam de um grande contingente de trabalhadores em suas indústrias, os interesses das elites globalizadas, expressos nas políticas do Banco Mundial, trouxeram conseqüências evidentes para a educação. Esses interesses, ao serem analisadas as políticas públicas educacionais, fazem surgir uma correlação de forças que pode influenciar o processo de elaboração e aplicação das políticas educacionais locais.

Para se compreender o significado das políticas educacionais em Curitiba, é necessário examinar os objetivos dos planos implantados, as concepções educacionais neles inseridas e a forma como se traduziram na prática pedagógica.

\section{Os ideários, concepções e práticas adotados na rede municipal de ensino de Curitiba no período 1979-1992}

\section{A gestão do prefeito Jaime Lerner (1979-1983) - uma concepção pedagógica liberal e tecnicista}

O período compreendido entre 1979 e 1983 corresponde ao segundo mandato do prefeito Jaime Lerner em Curitiba, cidade que ele havia administrado, como prefeito nomeado no regime ditatorial, entre 1971 e 1975, quando a educação municipal fora adaptada à Lei $n^{\circ}$ 5.692/71, de inspiração tecnicista. Seu discurso técnico e sua vinculação a organismos internacionais garantiam-lhe a conexão com o pensamento neoliberal, acompanhada de uma aparente imparcialidade sobre as questões urbanas.

A relação entre expansão da educação e planejamento da cidade, com base nos preceitos de ordem técnica, sobrevive na geração de desigualdade entre as populações que desfrutam de condições de permanência na rede urbana e aquelas que dela são alijadas, 
posto que consideradas inadequadas ao projeto neoliberal.

A partir de 1971, considerando principalmente que o aumento da demanda escolar se verificava de modo especial em áreas urbanas periféricas, a Prefeitura Municipal de Curitiba adotou três diretrizes fundamentais em sua política educacional: expandir a rede escolar, construindo novas unidades em áreas mais carentes; diversificar o atendimento de acordo com as características e necessidades locais; e prestar outros serviços sociais às áreas servidas por escolas (CURITIBA, 1975a). De acordo com a nova lei, em 1973 foram criados os serviços de Supervisão Escolar e Orientação Educacional, com as atribuições que lhes eram designadas.

Em 1975, considerando as características socioeconômicas das comunidades que eram atendidas pela educação municipal e a política de atuação da Diretoria de Educação, optou-se por implantar um Currículo único para todas as Unidades Escolares da Rede Municipal de ensino. Iniciava-se a gestão do prefeito Saul Raiz (1975-1979), que deu sequência à expansão da rede escolar municipal, aumentou o número de professores atuantes no sistema e construiu prédios escolares de acordo com as necessidades nele identificadas.

No período compreendido entre 1979 e 1983, sendo prefeito Jaime Lerner, tomou corpo o projeto de planejamento urbano da cidade, com financiamentos dos governos federal e estadual e do Banco Mundial (SÁNCHEZ, 2003). A Diretoria de Educação procurou "planejar, dirigir, coordenar e controlar a educação dentro da política adotada e obedecendo a legislação em vigor", conforme expresso na Portaria n ${ }^{0}$ 09/79 - Regulamento do Departamento de Educação (CURITIBA, 1980, p. 5), o que significava atender à Lei ${ }^{\circ}$ 5.692/1971. Com esse objetivo, foram previstas ações em quatro programas, a saber: 1 . Dinamização da estrutura organizacional; 2. O aluno; 3. O currículo; 4. Recursos humanos, considerando-se como prioridade a "sistematização das ações desenvolvidas pelas divisões de Ensino, Treinamento Pedagógico e Atendimento ao Estudante, no sentido de consolidar a nova estrutura organizacional" (CURITIBA, 1980, p. 8). A teoria do capital humano, somada às linhas de ação do Banco Mundial, difundiam o ideal meritocrático, de acordo com o qual cada cidadão poderia conquistar trabalho digno e usufruir de seus resultados, se fizesse por merecer essa condição.

Buscou-se descentralizar os serviços técnico-pedagógico-administrativos, implementando-se a sistemática da Orientação Educacional e da Supervisão Escolar, além de se implantar um sistema de informação estatística, documentação e registro da vida escolar. A racionalização das ações administrativas, a busca da melhoria de desempenho dos diretores e a descentralização do processo de tomada de decisões direcionaram as ações no período. A escola, em sua organização, deveria ser eficiente, racional e produtiva, com processos ordenados e operacionais que oferecessem o produto que dela se esperava. $\mathrm{O}$ aluno e o professor exerceriam papéis secundários, de acordo com o processo planejado por especialistas.

Outras preocupações básicas que orientaram o trabalho na Rede Municipal de Ensino foram a minimização dos percentuais de reprovação e a melhoria da qualidade do ensino. Para isso, a Divisão de Treinamento Pedagógico realizou cursos de treinamento e atualização, inseridos no Programa Recursos Humanos, capacitando $73 \%$ do total de professores de pré a $4^{\mathrm{a}}$ série, equivalente a 1.237 docentes. Além disso, para minimizar os custos inicialmente previstos em até $90 \%$, foram utilizados como docentes dos cursos de treinamento e atualização os profissionais que atuavam no próprio Departamento de Educação, nas Diretorias e Unidades Escolares (CURITIBA, 1981).

De um modo geral, os resultados obtidos com o treinamento realizado foram considerados satisfatórios, diante da constatação de que o atingimento dos objetivos 
educacionais ocorre em longo prazo (CURITIBA, 1981).

No início dos anos 80 , contudo, frente às reivindicações dos movimentos sociais de bairro e dos movimentos sindicais, que questionavam as políticas urbanas relativas à habitação, ao transporte público e ao saneamento, sob influência do processo de abertura democrática no país, o processo de urbanização teve que dar lugar à implantação de equipamentos sociais em áreas periféricas, o que incentivou a criação de mecanismos de participação popular.

\section{A gestão dos prefeitos Maurício Fruet (1983-1985) e Roberto Requião (1985-1989) - uma tendência progressista}

Maurício Fruet, eleito prefeito de Curitiba em 1983, foi indicado por José Richa, primeiro governador eleito após a ditadura, no Paraná, pertencente à oposição. Representava a expectativa popular de mudanças, diante da profunda crise econômica e social em que se vivia. No entanto, a política econômica do país mantivera-se a mesma dos anos anteriores, e, apesar de os novos governantes acenarem com avanços significativos no plano sócio-político, foi necessário conviver com práticas retrógradas, que impediam maior participação da população.

A proposta de democracia participativa, lema da campanha da oposição, sinalizava uma política de superação da postura tecnicista, exigindo uma ação mais crítica e democrática por parte dos professores. Com base nesses pressupostos, foi publicado o "Manifesto Político de Educação para uma Escola Aberta" que, aprovado por Maurício Fruet, deu início a um projeto educacional distinto, fundamentado na pedagogia históricocrítica, que delineou uma nova tendência na educação municipal.

$\mathrm{Na}$ gestão de Maurício Fruet também foi concluído o Plano Municipal de Desenvolvimento Urbano (PMDU), que propunha diretrizes básicas para um novo modelo de desenvolvimento, com o fortalecimento dos órgãos setoriais da Prefeitura, denominados Administrações Regionais, em número de nove. Como consequência, foram descentralizadas as ações do governo e as Regionais ganharam relativa autonomia.

No Departamento de Educação, iniciavam-se as discussões em torno do Currículo Básico para a escola pública municipal, com o objetivo de atender às necessidades da classe trabalhadora.

A democratização da escola brasileira nos anos 70 havia sido marcada pelo aumento da oferta de vagas, garantindo o acesso à escola da maioria da população. A profissionalização que se propunha visava a atender prioritariamente a classe trabalhadora, para a qual se apresentava um meio de acesso ao mercado de trabalho. Segundo Zanella (2003, p. 185), essas escolas eram "[...] paliativos educacionais das classes dominantes oferecidos às classes populares". Isto significava uma educação "em doses homeopáticas", com a negação do saber elaborado à classe produtiva. Na visão de Gramsci (1999, p. 136), seria uma forma sutil de "perpetuar as diferenças sociais.

Na nova tendência, a função da escola não seria formar para o mercado de trabalho, no modelo da escola burguesa, mas proporcionar ao educando uma formação geral, política e emancipatória que o instrumentalizasse para que pudesse fazer uso de seus conhecimentos também no mercado de trabalho. A escola deveria garantir aos educandos o acesso ao saber elaborado, pela superação do senso comum.

Tais foram as ideias que impregnaram o Manifesto, o qual não trouxe uma proposta curricular, mas indicou uma nova maneira de pensar a escola e uma nova postura para o professor. O ponto de partida seria a realidade do aluno, a partir da qual the seria dada a possibilidade de acesso ao conhecimento sistematizado e historicamente produzido. 
Maurício Fruet percebeu que a escola significava a única possibilidade de as camadas populares participarem do projeto de reconstrução da sociedade e, assim, assumiu o compromisso político de implantar a escola proposta no Manifesto.

O novo projeto diferenciava-se de uma política liberal, cujas políticas públicas sociais e educacionais são mínimas, privando o educando do acesso ao saber elaborado, precarizando a formação de professores e reduzindo a qualidade da educação (VIEIRA, 2010).

Assim, de encontro à concepção liberal, as diretrizes da Rede Municipal de Ensino de Curitiba para o período 1983-1985 propuseram não mais formar os alunos como "instrumentos a serem manipulados pelo sistema capitalista", mas sim dotá-los "dos requisitos básicos para a sobrevivência num mundo em mudança, aliados ao despertar de uma consciência crítica e atuante na sociedade a que pertencem" (CURITIBA, 1983, s.p.).

Como o Manifesto não trazia uma proposta curricular, mas procurava indicar uma maneira diferente de se pensar a escola, com um novo papel para o professor, passou-se às discussões sobre o Currículo Básico, que foi implantado em 1984 e exigia o estabelecimento de uma política efetiva de formação continuada do corpo docente.

A nova proposta exigia uma política de aperfeiçoamento sistemático dos professores, para que pudessem identificar as contradições emanadas das relações sociais e elaborar um currículo escolar em que as necessidades dos alunos fossem contempladas. Inúmeras oportunidades de formação continuada foram proporcionadas aos docentes, facilitando-lhes a participação mediante flexibilização de horários e estímulos para promoção na carreira docente.

Os educadores se ressentiam de sua formação pouco politizada e voltada exclusivamente ao tecnicismo. As novas exigências de repensar a ação educativa, o papel do professor, de forma a atuar na descentralização das decisões, envolvendo pais, alunos e professores no processo educacional, tornavam imperiosa a oferta de uma formação continuada adaptada aos novos desafios.

Embora enfrentando limitações de ordem burocrática, financeira, social e comportamental, a execução da nova política prosperou, sendo evidenciados o papel político do professor e sua valorização.

Assumindo a Prefeitura Municipal de Curitiba para o período 1985-1989, o prefeito Roberto Requião manifestou seu compromisso com a democratização do conhecimento pela ampliação da oferta escolar, o compromisso da ação escolar com a transformação da sociedade e a integração da ação educativa com as demais ações sociais. Para ele, a ampliação da oferta escolar era considerada uma "forma de pagamento da dívida social para com a classe trabalhadora" (CURITIBA, 1986, p. 7). Essas grandes idéias se consubstanciaram no Currículo Básico de 1988, que "representa um projeto pedagógico, produto de estudos, reflexões e debates, sistematizados no $4^{\circ}$ Plano de Educação, gestão 85-88, reunindo os esforços de vários profissionais da própria rede e de algumas universidades" (TOMACHESKI, 2003, p. 21).

O Currículo Básico, resultante da reflexão sobre essas metas, trouxe inúmeras oportunidades de aperfeiçoamento profissional, uma vez que era fundamental que os docentes e o pessoal administrativo estivessem preparados para trabalhar com a Pedagogia Histórico-Crítica. Só assim haveria o resgate da escola como parte do sistema social, em seu papel de instrumentalizar as pessoas mediante a aquisição de conhecimentos sistematizados para a prática da cidadania.

De acordo com a Pedagogia Histórico-Crítica, não interessava o saber sistematizado como tal, mas como "um meio para o crescimento do aluno" (SAVIANI, 2008, p. 74). À formação dos alunos não interessava assimilar o saber enquanto resultado, 
mas sim a aprendizagem do processo de sua produção, historicamente considerada.

A oportunidade de acesso, aliada à garantia de uma educação de boa qualidade, implicava numa maior permanência do aluno na escola, o que motivou a implantação da Escola Integrada de Período Integral, dentre escolas que estivessem localizadas na periferia da cidade, atendessem a famílias com baixo nível de renda e apresentassem elevado índice de reprovação e evasão escolar.

Esse processo de mudança de política educacional no município propiciou elevada quantidade de eventos voltados à formação continuada docente, desenvolvidos pela Divisão de Aperfeiçoamento Profissional. Nem todos os professores, no entanto, entendiam muito bem a nova tendência em seus pressupostos e componentes, razão pela previa-se a participação de todos nessas discussões, procurando assegurar um desenvolvimento coerente no processo de implantação da nova tendência.

\section{A educação no período 1988-1992 - conciliação de tendências}

Assumindo o cargo de prefeito para o período 1989/1992, Jaime Lerner designou uma comissão para estudar a situação das Escolas em Tempo Integral, uma vez que era seu objetivo incentivar o projeto de ampliação do tempo de permanência do aluno na escola, implantando os Centros de Educação Integral. Identificando carências nas Escolas em Tempo Integral, o relatório dessa comissão propôs medidas que permitiriam um redirecionamento do processo de implantação e acompanhamento daquelas escolas.

Destaca Germani (2006, p. 98), que essa ampliação do tempo de permanência do aluno na escola, embora tivesse ocorrido, configurava a implantação de "outra proposta de escola de tempo integral, com estruturas físicas bem diferentes. A visão arquitetônica dessa nova gestão buscava, além de uma nova concepção de espaço escolar, um barateamento das obras", esquecendo-se de que um ponto fundamental, componente básico de uma Pedagogia Histórico-Crítica, era a realidade de cada comunidade educacional.

Com o objetivo de fundamentar, discutir e aprofundar as diretrizes da nova política de educação, foi realizado o $1^{\circ}$ Seminário Municipal Interno para Elaboração de Diretrizes de Educação, de agosto a novembro de 1989. Os resultados obtidos fundamentaram a elaboração do Plano de Ação da Secretaria Municipal da Educação, o qual continha as metas e programas que já vinham sendo desenvolvidos e aos quais se daria continuidade na gestão do prefeito Jaime Lerner (CURITIBA, 1989).

Foram estabelecidas oito metas, dentre as quais se destacavam a meta 1 , que previa a organização de um ensino de qualidade que tivesse como prioridade "a ação pedagógica comprometida com a democratização da sociedade brasileira, a universalização do saber e o resgate da confiabilidade da escola pública"; a meta 2, que definia a "implantação gradativa dos Centros de Educação Integral, e efetivação das Escolas de Tempo Integral"; outras metas tratavam do desenvolvimento da educação ambiental, do atendimento à educação pré-escolar, ao atendimento educacional especializado aos portadores de excepcionalidade, o compromisso como a educação de jovens e adultos, a democratização do acesso ao esporte e ao lazer, e a ampliação do sistema de informatização da Secretaria Municipal da Educação, para que se pudessem agilizar os serviços administrativos e pedagógicos (CURITIBA, 1991, p. 5).

Os documentos informam que, em 1990, foram implantadas consultorias para dar suporte à equipe pedagógica do Departamento de Ensino e instituiu-se o assessoramento direto aos professores da Rede Municipal de Ensino. O magistério municipal, porém, descontente com as condições de trabalho e a nova política implantada, deflagrou greve 
reivindicando alterações. Além disso, do ponto de vista da qualidade da educação ofertada, havia preocupação com os índices de evasão e repetência, considerados alarmantes no período 1888-1990, com percentuais em torno de $30 \%$ e $23 \%$, respectivamente. Para buscar alternativas voltadas a reverter essa situação, formou-se um grupo de discussão, composto por docentes da Rede Municipal de Ensino e da Universidade Federal do Paraná, de cujos estudos resultou a proposta pedagógica que veio a servir de referência para os Centros de Educação Integral que viessem a ser implantados. A política de capacitação de recursos humanos, com a viabilização de melhores condições de trabalho aos profissionais de educação integrou as orientações da proposta e, ao final de 1991, o Relatório de Atividades dava conta de haverem sido realizadas:

12 Semanas de Estudos Pedagógicos;

121 Cursos, Seminários, Encontros;

229 Turmas;

7033 Inscrições;

67 Consultorias (CURITIBA, 1991, p. 20).

Percebe-se que os professores participavam dos eventos destinados à sua capacitação, mas ao mesmo tempo se ressentiam da falta de tempo para estudo e aprofundamento das questões. Observa Vieira (2010) que os docentes desejavam não só aproveitar as oportunidades de desenvolvimento profissional, mas queriam torná-las mais significativas e proveitosas, para que melhores resultados trouxessem ao trabalho pedagógico.

Esse trabalho de formação continuada estava alinhado ao objetivo dos Centros de Educação Integral, que era promover "a instrumentação do indivíduo, através da garantia do acesso ao saber elaborado, articulado com o saber popular, para que o mesmo possa [pudesse] atuar na sociedade como agente de transformação" (CURITIBA, 1992, p. 21).

Aponta Germani (2006, p. 64), que o Conselho Estadual de Educação, ao analisar a proposta de implantação dos CEIs, "[...] considerou que o aumento da jornada escolar diária emergia como sinal de progresso na melhoria da qualidade do ensino", mas que essa análise pontual, restrita ao tempo de permanência do aluno na escola, não abrangia aspectos ligados à realidade e à condição social dos educandos.

Com base nessas reflexões, percebe-se que a qualidade visada para a educação do Município - vinculada a maior eficiência e eficácia no desenvolvimento do projeto pedagógico da Rede Municipal de Ensino -, gradativamente, ia se identificando com o conceito à época difundido, no Brasil, de "qualidade total", retornando a um conceito liberal e tecnocrático de educação.

\section{Considerações Finais}

Do estudo da formação de professores na Rede Municipal de Ensino de Curitiba, em sua relação com ideários, concepções e práticas diferenciadas, no período 1979-1992, correspondente à gestão dos prefeitos Jaime Lerner (1979-1983 e 1989-1992), Maurício Fruet (1983-1985) e Roberto Requião (1985-1989), constata-se que tanto o liberalismo quanto o progressismo exerceram influência na definição das políticas educacionais. Cada uma dessas políticas resultou em concepções e práticas que exigiram uma formação docente específica que pudesse executá-las conforme proposto.

É de se considerar, no entanto, que ideários, concepções e práticas educacionais 
estão imbricados com concepções de sociedade, de cultura e de ser humano que não são suscetíveis de mudanças conforme a intenção de agentes externos ou a implantação de projetos elaborados por equipes externas. A descontinuidade de programas implantados com a substituição de propostas em andamento e a consequente exigência de alterações no trabalho docente representam falta de respeito aos professores como sujeitos da história e protagonistas da educação.

Conforme observa Poulantzas (2000), porém, a classe dominante não raro se vê compelida a fazer concessões, para garantir o alcance de seus objetivos. Dessa forma, no retorno à Prefeitura Municipal de Curitiba, em seu terceiro mandato, o prefeito Jaime Lerner optou por assumir uma posição conciliatória. Sabidamente de postura liberal e tecnicista, ao suceder o prefeito Roberto Requião, em 1989, não só manteve como propiciou o aprofundamento dos estudos sobre a Pedagogia Histórico-Crítica, uma das reivindicações da categoria docente.

A comparação entre os ideários fundamentados no liberalismo e no progressismo, que resultaram na adoção das concepções tecnicista e histórico-crítica, as quais geraram práticas a elas adequadas e a necessidade de formação docente com estilos diferenciados, permite que sejam esboçadas algumas considerações a respeito.

a) Ideário, concepção, práticas e formação docente, quer provenham da autoridade instituída ou de exigências da sociedade participante, interpenetram-se reciprocamente e demandam atuação coerente na esfera educacional.

b) A passagem de uma concepção tecnicista para uma tendência histórico-crítica, em função das características do tecnicismo, gera questões de resolução aparentemente mais simples do que a situação inversa, que pode provocar conflitos de maior monta entre o poder público e a categoria docente. Com efeito, no caso em estudo, o retorno à pedagogia tecnicista, sem a participação docente, foi uma das causas da prolongada greve dos professores municipais.

c) Em todos os períodos estudados, com predominância ora do tecnicismo ora do progressismo, a formação continuada de professores foi considerada o elemento-chave para a adequação da prática pedagógica aos ideários e concepções vigentes.

d) Em relação ao município de Curitiba, independentemente do ideário pedagógico adotado, a expansão da educação manifesta como referencial contínuo a vinculação ao planejamento urbano da cidade.

Os estilos de formação docente no município de Curitiba, em suma, em relação ao período 1979-1992, não estiveram afastados dos ideários, concepções e práticas determinantes, sendo considerados indispensáveis para sua concretização.

\section{REFERÊNCIAS}

AZEVEDO, J. M. L. A educação como política pública. Campinas, SP: Autores Associados, 2004. (Coleção polêmicas do nosso tempo; vol. 56).

BLOCH, M. L. B. Apologia da história ou o ofício do historiador. Rio de Janeiro: Jorge Zahar Ed., 2001.

BRASIL. Legislação. Lei de Diretrizes e Bases da Educação Nacional. Lei no 4.024/1961. Disponível em < http://www.planalto.gov.br/leg.asp>. Acesso em: 27 out. 2011.

Legislação. Lei $n^{\circ}$ 5.692, de 11 de agosto de 1971. Disponível em < http://www.planalto.gov.br/ccivil_03/Leis/L5692.htm>. Acesso em: 27 out. 2011. 
COSTA, V. A. A. Memória da Rede Municipal de Ensino de Curitiba (1963-1982). . Boletim da Casa Romário Martins. Curitiba: Fundação Cultural de Curitiba, v. 30, n. 133, mar. 2007.

CURITIBA. Departamento do Bem Estar Social. Diretoria de Educação. Relatório de 1963-1966. Curitiba: Prefeitura Municipal de Curitiba, 1966.

Curitiba, 1968.

Plano de educação. Curitiba: Instituto de Pesquisa e Planejamento Urbano de

. Relatório da gestão Omar Sabbag 1967/1969. Curitiba: PMC, 1969.

. Educação. Curitiba: Prefeitura Municipal de Curitiba, 1975a.

. Plano de educação. Plano curricular. vol. III-A. Departamento do Bem Estar Social. Diretoria de Educação. Curitiba: Prefeitura Municipal de Curitiba, 1975 b.

. Relatório geral de atividades de 1976. Departamento do Bem Estar Social. Curitiba: Prefeitura Municipal de Curitiba, 1976.

. Relatório geral de atividades. Departamento de Educação. Curitiba: Prefeitura Municipal de Curitiba, 1979.

- Relatório geral de atividades da Diretoria de Educação à vista do Plano de Ação anual. Diretoria de Educação. Curitiba: Prefeitura Municipal de Curitiba, 1980.

Relatório geral de atividades. Departamento de Educação. Curitiba: Prefeitura Municipal de Curitiba, 1981.

Relatório geral de atividades. Divisão de Treinamento Pedagógico. Diretoria de Educação. Curitiba: Prefeitura Municipal de Curitiba, 1983.

. Plano de educação do município. Gestão 1986/1988. Curitiba: Prefeitura Municipal de Curitiba, 1986.

. Relatório anual das atividades. Secretaria Municipal da Educação. Prefeitura Municipal de Curitiba. Curitiba: Prefeitura Municipal de Curitiba, 1989.

. Relatório anual. Secretaria Municipal da Educação. Curitiba: Prefeitura Municipal de Curitiba, 1991.

- Proposta pedagógica dos Centros de Educação Integral. Coordenadoria Especial de Implantação dos Centros de Educação Integral. Curitiba: Prefeitura Municipal de Curitiba, 1992.

FARGE, A. O sabor do arquivo. Trad. Fátima Murad. São Paulo: Editora da Universidade de São Paulo, 2009.

GERMANI, B. Educação de tempo integral: passado e presente na Rede Municipal de Ensino de Curitiba. 2006. Dissertação (Mestrado em Educação) - Pontifícia Universidade Católica do Paraná, Curitiba, 2006.

GOMES, F. G. Conflito social e welfare state: Estado e desenvolvimento social no Brasil. Revista de Administração Pública, v. 40, n. 2. Rio de Janeiro, mar./abr. 2006.

GRAMSCI, A. Cadernos do cárcere. Introdução ao estudo da filosofia de Benedetto Croce, v. 1. Rio de Janeiro: Civilização Brasileira, 1999. 
Cadernos do cárcere. Maquiavel, notas sobre o Estado e a política, v.2. Rio de Janeiro: Civilização Brasileira, 2000.

MIGUEL, M. E. B. A formação do professor e a organização social do trabalho. Curitiba: Ed. da UFPR, 1997.

; VIEIRA, A. M. D. P. As políticas educacionais da Rede Municipal de Educação de Curitiba e a implantação de novas práticas nas escolas (1963-1996). CONGRESSO BRASILEIRO DE HISTÓRIA DA EDUCAÇÃO, 4, 2006, Goiânia. Anais... Goiânia, 2006. 1 CD-ROM.

NEVES, B.V.F. et al. Caracterização dos planos curriculares de educação da Rede Municipal de Ensino de Curitiba. Monografia. Curitiba: UFPR, 1988. (mimeo).

POULANTZAS, N. O estado, o poder, o socialismo. São Paulo: Paz e Terra, 2000.

SÁNCHEZ, F. A reinvenção das cidades para um mercado mundial. Chapecó: Argos, 2003.

SAVIANI, D. As concepções pedagógicas na história da educação brasileira. Navegando na história da educação brasileira. HISTEDBR, 2005. Disponível em <http://www.histedbr.fae.unicamp.br/navegando/artigos_frames/artigo_036.html.>. Acesso em: 14 mar. 2009.

Pedagogia histórico-crítica: primeiras aproximações. Campinas, SP: Autores Associados, 2008. (Coleção educação contemporânea).

TOMACHESKI, E. G. B. A trajetória da educação matemática na Rede Municipal de Ensino de Curitiba: do currículo pensado ao vivido. 2003. Dissertação (Mestrado em Educação) - Pontifícia Universidade Católica do Paraná, Curitiba, 2003.

VIEIRA, A. M. D. P. Caminhos e descaminhos na formação continuada de professores: as políticas públicas da Rede Municipal de Ensino de Curitiba (1963 a 1996). Tese (Doutorado em Educação). Pontifícia Universidade Católica do Paraná. 2010.

ZANELLA, J. L. O trabalho como princípio educativo do ensino. 2003. Tese (Doutorado em Educação) - Universidade Estadual de Campinas, Campinas 2003. 